\title{
Comparison of Provision of Stroke Care in Younger and Older Patients: Findings from the South London Stroke Register
}

\author{
Siobhan L. Crichton, ${ }^{1}$ Charles D. A. Wolfe, ${ }^{1,2}$ Anthony G. Rudd, ${ }^{3}$ and Christopher McKevitt ${ }^{1}$ \\ ${ }^{1}$ Division of Health and Social Care Research, King's College London, London SE1 3QD, UK \\ ${ }^{2}$ NIHR Biomedical Research Centre, Guy's and St. Thomas' NHS Foundation Trust and King's College London, London, \\ SE1 9RT, UK \\ ${ }^{3}$ Department of Ageing and Health, St. Thomas' Hospital, Guy's and St. Thomas' NHS Foundation Trust, London, SE1 7EH, UK
}

Correspondence should be addressed to Siobhan L. Crichton, siobhan.crichton@kcl.ac.uk

Received 28 November 2011; Revised 30 January 2012; Accepted 11 February 2012

Academic Editor: Halvor Naess

Copyright (๑) 2012 Siobhan L. Crichton et al. This is an open access article distributed under the Creative Commons Attribution License, which permits unrestricted use, distribution, and reproduction in any medium, provided the original work is properly cited.

\begin{abstract}
Background. Evidence-based stroke care should be available to all patients. However, evidence exists of inequalities according to age. This study compared access to care for younger adults to that for over 65s. Methods. Using population-based data from 4229 patients with first-ever stroke between 1995 and 2010, associations between age and 21 care indicators were investigated using multivariable logistic regression. Results. Age was not associated with stroke unit admission for ischaemic stroke $(P=0.666)$. Younger PICH patients were least likely to be admitted to stroke units $(P=0.001)$, instead treated on neurosurgical or ICU wards. Younger age was also associated with admission to neurosurgery or ICU after SAH $(P=0.006)$, increased occupational or physiotherapy at 1 year $(P=0.043)$, and contact with a GP 3 months after stroke $(P<0.001)$. Conclusion. Younger patients have equal or greater access to evidence-based care. However, there is a need to ensure that services meet the needs of this group.
\end{abstract}

\section{Introduction}

Stroke incidence increases with age but a significant proportion of strokes occur in younger people: around 30\% of people recruited to the multiethnic South London Stroke Register are under 65 years of age [1]. A range of social consequences affect younger people with stroke, including an inability to return to work $[2,3]$. A recent study estimated the loss of earnings attributable to stroke in the UK, for those younger than 65 , to be approximately $£ 1.5$ billion or $15 \%$ of the total cost of stroke to the UK economy [4].

Evidence-based stroke care is associated with improved patient outcomes [5]. The National Clinical Guideline for Stroke (England and Wales) recommends that all patients receive access to evidence-based care appropriate to their condition and regardless of age [5]. However, there is evidence of inequalities in the provision of care and secondary prevention management according to age $[1,6-13]$. Studies have found younger stroke patients more likely to be admitted to hospital $[1,10]$ and receive brain imaging $[1,10-13]$ but less likely to have physiotherapy $[1,10]$, access to organised stroke care [6], and appropriate secondary prevention medication [8]. Contrastingly, other studies have found improved secondary prevention [9] and access to outpatient physiotherapy or occupational therapy [1] to be associated with younger age.

While admission to a stroke unit improves outcome across all age groups [5], the relative increase in survival rates and decrease in levels of dependency associated with stroke unit admission has been found to be the greatest among the 18-64-year age group $[6,14]$. It is therefore particularly important to ensure this age group are admitted to stroke units to ensure they benefit from the associated improvements in outcome.

Existing studies vary in their definition of younger age and have not looked specifically at provision of care for those under 65 years. Therefore, this study focuses on the role of age as a predictor of access to evidence-based care, including 
risk factor management, acute care, and rehabilitation therapies, in an unbiased sample of younger and older patients with stroke from a multiethnic population-based cohort in south London.

\section{Methods}

2.1. Study Population. The South London Stroke Register (SLSR) is an ongoing population-based register, established in January 1995, which records all first-ever strokes in patients of all ages within a defined area of south London. The source population was 271817 with $63 \%$ white, $15 \%$ black African, 9\% black Caribbean, 4\% black other, and 9\% of other ethnic groups (source: Census 2001 [15]).

2.2. Data Collection. Methods used in data collection have been previously described [16] and are summarised below. To maximise case ascertainment and reduce bias in studies, the SLSR uses multiple overlapping sources of notification $[17,18]$. Completeness of case ascertainment has been estimated to be between 75 and $84 \%$ [17]. Stroke was defined using WHO criteria [19] and classified as ischaemic stroke, primary intracerebral haemorrhage (PICH), or subarachnoid haemorrhage (SAH) based on brain imaging (computed tomography (CT) or magnetic resonance imaging (MRI)) within 30 days of stroke onset, necropsy examination, or cerebrospinal examination (SAH only). Where there was no known pathological confirmation of stroke subtype patients were classified as undefined. Initial data were collected within 48 hours of notification to the SLSR where possible. Data were collected at onset and at 3 months, 12 months and annually after stroke by a study nurse or specially trained field worker. Sociodemographic data collected at the initial assessment included age, ethnicity (categorised as white, black, or other), socioeconomic status (classified as manual or nonmanual according to the Registrar General's occupational codes [20]), and employment status prior to stroke, categorised as full time employed (more than $30 \mathrm{hrs}$ per week), part time employed (less than $30 \mathrm{hrs}$ per week), unemployed and looking for work, unable to work due to disability or ill health, carer (for home, family, or dependents), retired, or unknown. Incontinence, motor deficits, and Glasgow Coma Score (categorised as 3-8, 9-12, 13-15) [21] were also collected in the acute phase following stroke onset and used as a proxy for stroke severity.

We defined patients as being of younger if aged 18-64 years at the time of stroke, based on the default retirement age in the UK. Younger patients were further categorised into two age groups, 18-54 years and 55-64 years.

2.3. Indicators of Care. A range of indicators, suggested to be useful proxies for overall quality of care $[1,5]$, were derived. Four indicators of short-term care were included: admission to hospital, admission to an appropriate specialist unit, more than $50 \%$ of hospital stay spent on an appropriate specialist unit, and brain imaging (using CT or MRI). The National Clinical Guideline for Stroke (England and Wales) [5] recommends that all patients with stroke be treated on a specialist stroke unit. However, for patients with an SAH admission to an intensive care unit (ICU) or neurosurgical ward would be appropriate. Therefore, where patients had a SAH, an appropriate specialist ward was defined as a neurosurgical ward or ICU. For all other patients admission to an appropriate unit was defined as stroke unit admission. Receipt of thrombolysis was not included in this study due to low numbers of patients receiving the therapy within each age group.

There were 11 indicators relating to the appropriate management of risk factors. Information on the prior to stroke diagnosis and management of risk factors, including hypertension ( $>140 \mathrm{~mm} \mathrm{Hg}$ systolic or $>90 \mathrm{~mm} \mathrm{Hg}$ diastolic), atrial fibrillation, and diabetes mellitus, was obtained using general practice records and hospital records at baseline. At 3 - and 12-month follow-up information was collected using patient self-report. Appropriate medication use in patients with a diagnosis of hypertension or diabetes mellitus was recorded prior to stroke and at 3 and 12 months after stroke. In ischaemic stroke patients, the use of antiplatelets was recorded at 3 and 12 months after stroke. Anticoagulation in patients with atrial fibrillation was recorded in all patients prior to stroke and in ischaemic stroke patients at 3 and 12 months after stroke.

In eligible patients, provision of physiotherapy, occupational therapy $(\mathrm{PT} / \mathrm{OT})$, and speech and language therapy (SALT) in the month prior to the 3- and 12-month followups was recorded. Eligibility for PT/OT was defined as recorded motor or sensory deficits in the arm, hand, or leg while. For SALT, patients with dysarthria, dysphasia, or a failed swallow test were considered eligible. Contact with a general practitioner (GP) was also recorded at 3 and 12 months after stroke.

2.4. Statistical Methods. Univariable analyses examined differences between sociodemographic factors, case mix factors, and indicators of care across the three age groups using $\chi^{2}$ tests or Fisher's exact test as appropriate. Multivariable logistic regression models were used to analyse associations between age and the indicators of care, while adjusting for time trends in the receipt of care and controlling for possible sociodemographic (ethnicity, gender, and socioeconomic status) and case mix (Glasgow coma score, stroke subtype, motor and swallow deficits, and urinary incontinence) differences. Interaction terms between age and year of stroke were added to multivariable models to examine whether any disparities between age groups had varied across the 16 years of the study.

Models of indicators of acute care were analysed firstly across all patients and then in those with ischaemic stroke, $\mathrm{PICH}$, and SAH separately. Analyses on admission to appropriate specialist units were restricted to those admitted to hospital and analyses of rates of patients spending at least $50 \%$ of stay on appropriate units were carried out firstly among all admitted patients and then only those admitted to an appropriate ward at some point during their hospital stay. Multivariate models for admission to hospital and receipt of brain imaging in patients with PICH or SAH were not 
included due to the low number of younger patients not admitted or not receiving a scan $(n<10)$.

Sensitivity analyses were also conducted for the indicators of acute care. Only patients surviving at least 24 hours were included in the analyses of hospital admissions to account for differing rates of early deaths across age groups. For the other indicators only those in hospital for at least 3 days were included to remove patients who died very soon after admission and may not have had time to be admitted to an appropriate ward, or those with very mild strokes who are discharged home quickly.

Changes in access to care were controlled for in the analyses. However, the organisation of stroke services has changed considerably over the period of the study, therefore, further analyses of acute care indicators examined trends in rates of appropriate care prior to and from 2005 onwards.

Due to a change in the format of variables relating to the provision of therapies, in 2000 for the 3-month follow-up and 1999 for the one-year follow-up, data collected before and after these cut-off points were not comparable. Models for PT/OT and SALT at 3 months after stroke were therefore restricted to patients with first-ever stroke between 2001 and 2010 and at 12 months to patients with first-ever stroke between 1999 and 2010.

The use of anticoagulation therapy was not considered in multivariable analyses due to the very low number of surviving patients in the 18-54-year age group with a diagnosis of atrial fibrillation ( $N=17$ at time of stroke).

Analyses were restricted to patients without missing values. All tests were two-tailed with $P$ values $<0.05$ considered to be statistically significant. Statistical analyses were performed using Stata 11MP statistical software package.

2.5. Ethics. Informed written consent for participation in the study was obtained from all patients or their relatives. The study was approved by the St. Thomas' Hospital Research Ethics Committee (06/Q0702/147).

\section{Results}

Between January 1995 and December 20104338 patients were registered with first-ever strokes. Nine patients under 18 years of age at stroke onset were excluded leaving a total sample size of 4229. By 3 months after stroke 1102 (26.1\%) patients had died and 1069 (25.3\%) were lost to follow up. By 12 months after stroke 1409 (33.3\%) had died, 738 (17.5\%) were lost to follow up, and a further $164(3.8 \%)$ had not yet reached the one-year follow-up point. Patient characteristics, broken down by age group, are reported in Table 1 . The distribution of sociodemographic factors (gender, ethnicity, socioeconomic status, employment status) differed across age groups (all $P<0.001$ ) with the largest proportion of females in the over 65-year olds and the largest proportion of blacks observed in the 18-54-year olds.

The associations between age and indicators of acute care, for all patients, and broken down by stroke subtype, are presented in Table 2. In univariable analyses, younger patients were more likely to be admitted to hospital $(P=$
$0.007)$ and to have brain imaging $(P<0.001)$. They were also more likely to be admitted to a stroke unit, neurosurgical ward, or ICU, as appropriate, with $65.5 \%$ of $18-54$-year olds compared to $57.8 \%$ of $55-64$-year olds and $55.6 \%$ of over $65 \mathrm{~s}$ who were admitted to hospital spending at least some of their stay on an appropriate unit. After controlling for sociodemographic and case mix differences, the odds of being admitted to an appropriate unit across all patients did not significantly differ with age $(P=0.914)$. However, older patients with PICH were 3 times more likely to be admitted to a stroke unit than those aged $18-54$ years $(P=0.001)$. Conversely, in patients with SAH, the odds of admission to ICU or neurosurgical ward decreased with age $(P=0.006)$ with $86.6 \%$ of $18-54$-year olds, $85.7 \%$ of $55-64$-year olds and $58.1 \%$ of over $65 \mathrm{~s}$ admitted to one of these wards. For patients with ischaemic stroke, although a higher proportion of young patients were admitted to a stroke unit $(66.5 \%$ of $18-54$-year olds, $59.3 \%$ of 55-64-year olds, and $57.5 \%$ of over $65 \mathrm{~s}$ ) after adjusting for sociodemographic and case mix factors, the difference in odds of admission was not significant $(P=0.666)$.

In sensitivity analyses, where models were restricted to those with a length of stay in hospital of at least 3 days, the significance and size of these associations remained unchanged (data not shown).

Analyses of patients admitted prior to 2005 showed similar trends and significance levels to those reported above, with overall admission rates slightly lower than average. Similarly, while the overall proportion of patients accessing appropriate care was higher than average from 2005 onwards, differences across age groups remained. During this time period, the 55-64-year age group were found to have the highest rates of admission to appropriate wards. Across all patients, $85 \%$ of $55-64$-year olds were admitted to a stroke unit, ICU, or neurosurgical ward compared to $78 \%$ of $18-54$ year olds and $81 \%$ of over $65 \mathrm{~s}(P=0.0168)$. In patients with ischaemic stroke the rates were $82 \%$ for $18-54$ years, $90 \%$ for 55-64 years, and 83\% for over-65-year olds $(P=0.089)$. The corresponding figures for PICH patients were $61 \%, 80 \%$, and $73 \%(P=0.227)$ and $82 \%, 100 \%$, and $45 \%$ for SAH $(P=0.016)$.

The location of care for patients with PICH is summarised in Table 3. A higher proportion of younger patients with PICH were admitted to a neurosurgical ward or ICU with $55.5 \%$ of all patients of $18-54$ years admitted to one of these wards at some point, compared to $27.5 \%$ of $55-64$ years and $14.4 \%$ of over $65 \mathrm{~s}$. Among those not admitted to a stroke unit, $75 \%$ of $18-54$-year olds were treated in ICU or on a neurosurgical ward.

Table 4 reports the association between age and risk factor control prior to and at 3 and 12 months after stroke. A significantly lower proportion of younger patients were on treatment for hypertension prior to stroke $53.8 \%$ of 18 54 -year olds, $61.4 \%$ of $55-64$-year olds, and $61.7 \%$ of over $65 \mathrm{~s})$ and the difference remained significant in multivariable analyses $(P=0.029)$. However, by 3 months after stroke, the lowest rate of treatment was in the over-65-year age group and no significant trend was observed in any multivariable analyses at 3 or 12 months. 
TABle 1: Patient characteristics by age group.

\begin{tabular}{|c|c|c|c|c|c|}
\hline Patient characteristics, $n()$ & $\begin{array}{c}\text { Total } \\
(n=4229)\end{array}$ & $\begin{array}{c}18-54 \text { years } \\
(n=648)\end{array}$ & $\begin{array}{c}55-64 \text { years } \\
(n=671)\end{array}$ & $\begin{array}{c}65 \geq \text { years } \\
(n=2910)\end{array}$ & $P$ value \\
\hline \multicolumn{6}{|l|}{ Gender } \\
\hline Male & $2125(50.2)$ & $379(58.5)$ & $455(67.8)$ & $1291(44.4)$ & \multirow{2}{*}{$<0.001$} \\
\hline Female & $2104(49.8)$ & $269(41.5)$ & $216(32.2)$ & $1619(55.6)$ & \\
\hline \multicolumn{6}{|l|}{ Ethnic group } \\
\hline White & $3021(73.3)$ & $320(51.4)$ & $434(66.2)$ & $2267(79.7)$ & \multirow{3}{*}{$<0.001$} \\
\hline Black & $861(20.9)$ & $245(39.3)$ & $163(24.9)$ & $453(15.9)$ & \\
\hline Other & $241(5.9)$ & $58(9.3)$ & $59(9.0)$ & $124(4.4)$ & \\
\hline \multicolumn{6}{|l|}{ Socioeconomic status } \\
\hline Manual & $1996(47.2)$ & $243(37.5)$ & $352(52.5)$ & $1401(48.1)$ & \multirow{3}{*}{$<0.001$} \\
\hline Nonmanual & $929(22.0)$ & $179(27.6)$ & $137(20.4)$ & $613(21.1)$ & \\
\hline Unknown & $1304(30.8)$ & $226(34.9)$ & $182(27.1)$ & $896(30.8)$ & \\
\hline \multicolumn{6}{|l|}{ Employment status prior to stroke } \\
\hline Full time employed & $541(12.8)$ & $293(45.2)$ & $187(27.9)$ & $61(2.1)$ & \multirow{7}{*}{$<0.001$} \\
\hline Part time employed & $100(2.4)$ & $32(4.9)$ & $25(3.7)$ & $43(1.5)$ & \\
\hline Unemployed and looking for work & $132(3.1)$ & $85(13.1)$ & $44(6.6)$ & $3(0.1)$ & \\
\hline Unable to work due to ill health & $217(5.1)$ & $90(13.9)$ & $103(15.4)$ & $24(0.8)$ & \\
\hline Carer for family/dependents & $87(2.1)$ & $37(5.7)$ & $22(3.3)$ & $28(1.0)$ & \\
\hline Retired & $2905(68.7)$ & $22(3.4)$ & $215(32.0)$ & $2668(91.7)$ & \\
\hline Unknown & $244(5.8)$ & $89(13.3)$ & $75(11.2)$ & $83(2.9)$ & \\
\hline \multicolumn{6}{|l|}{ Stroke subtype } \\
\hline Infarction & $3145(74.4)$ & $365(56.3)$ & $515(76.8)$ & $2265(77.8)$ & \multirow{4}{*}{$<0.001$} \\
\hline $\mathrm{PICH}$ & $540(12.8)$ & $128(19.8)$ & $84(12.5)$ & $328(11.3)$ & \\
\hline SAH & $212(5.0)$ & $122(18.8)$ & $34(5.1)$ & $56(1.9)$ & \\
\hline Undefined & $332(7.9)$ & $33(5.1)$ & $38(5.7)$ & $261(9.0)$ & \\
\hline \multicolumn{6}{|l|}{ Glasgow comma score } \\
\hline$\leq 8$ & $671(16.5)$ & $115(18.5)$ & $93(14.6)$ & $463(16.5)$ & \multirow{3}{*}{$<0.001$} \\
\hline $9-12$ & $480(11.8)$ & $60(9.7)$ & $50(7.9)$ & $370(13.2)$ & \\
\hline $13-15$ & $2909(71.7)$ & 447 (71.9) & $494(77.6)$ & $1968(70.3)$ & \\
\hline
\end{tabular}

There was no difference in the odds of patients in different age groups receiving physiotherapy or occupational therapy 3 months after stroke $(P=0.461)$ (Table 5). However, by 1 year after stroke those aged $18-54$ were significantly more likely to still be having therapy compared to those of an older age $(P=0.043)$. Younger patients were also more likely to have had contact with their GP at 3 months after stroke $(P<0.001)$.

None of the interactions between age and stroke year were significant for any indicator of care, suggesting that differences across age groups occurred consistently throughout the study.

\section{Discussion}

This study compared patterns of care across stroke patients aged 18-54, 55-64, and over 65 years, by investigating management of risk factors prior to stroke, access to acute care, and provision of therapies and risk factor management over a 1-year period following stroke, using predefined indicators of care based on clinical guidelines $[1,5,10]$. There were no significant differences in the rates of admission to stroke units among ischaemic stroke patients. However, the likelihood of admission to a stroke unit in patients with PICH increased with age, with younger patients more likely to be treated on a neurosurgical ward or in ICU. In patients with an SAH, increasing age was also associated with lower likelihood of admission to neurosurgery or ICU. The proportion of patients with hypertension on antihypertensive medication prior to stroke was the lowest among 18-54-year olds but there was no association between risk factor control and age found at 3 and 12 months after stroke. Younger age was also found to be associated with increased GP contact at 3 months and greater likelihood of ongoing physiotherapy or occupational therapy at 1 year after stroke.

The National Clinical Guidelines for Stroke [5] recommends that "all patients with suspected stroke should be admitted directly to a specialist acute stroke unit following initial assessment either from the community or from the A\&E 


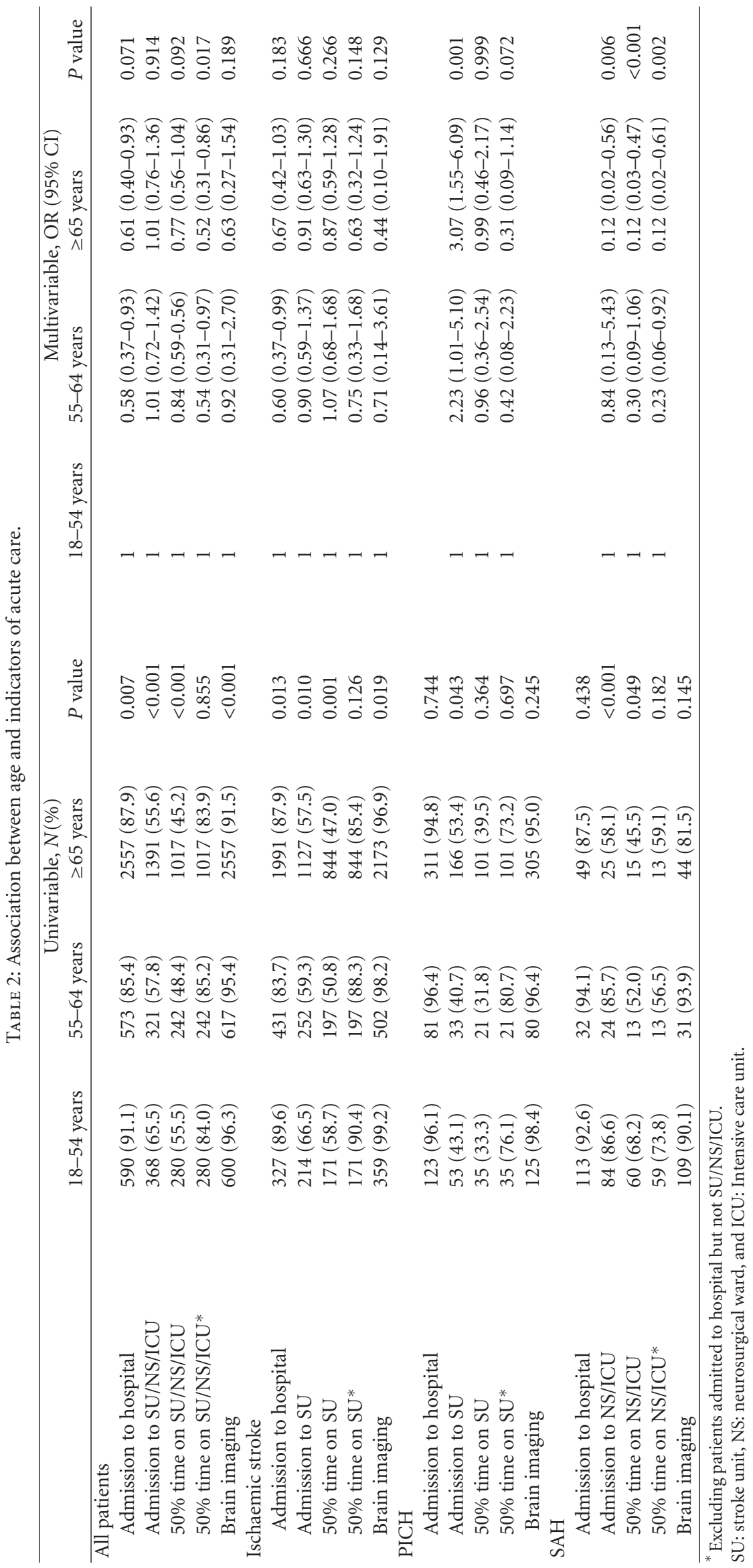


TABLE 3: Location of care of patients with PICH.

\begin{tabular}{|c|c|c|c|c|}
\hline & $18-54$ years, $N(\%)$ & $55-64$ years, $N(\%)$ & $\geq 65$ years, $N(\%)$ & $P$ value \\
\hline \multicolumn{5}{|c|}{ Admitted at any point during hospital stay } \\
\hline Stroke unit & $53(43.1)$ & $33(40.7)$ & $166(53.4)$ & 0.043 \\
\hline Neurosurgery & $32(31.7)$ & $7(10.1)$ & $11(4.1)$ & $<0.001$ \\
\hline ICU & $38(37.6)$ & $14(20.3)$ & $33(12.2)$ & $<0.001$ \\
\hline Neurosurgery or ICU & $56(55.5)$ & $19(27.5)$ & $39(14.4)$ & $<0.001$ \\
\hline \multicolumn{5}{|c|}{ Location of care of patients not admitted to a stroke unit } \\
\hline Neurosurgery & $20(36.4)$ & $6(15.0)$ & $4(3.5)$ & $<0.001$ \\
\hline ICU & $33(60.0)$ & $13(32.5)$ & $20(17.2)$ & $<0.001$ \\
\hline Neurosurgery or ICU & $42(76.4)$ & $17(42.5)$ & $21(18.1)$ & $<0.001$ \\
\hline
\end{tabular}

TABLE 4: Association between age and indicators relating to the management of risk factors.

\begin{tabular}{|c|c|c|c|c|c|c|c|c|}
\hline & \multicolumn{4}{|c|}{ Univariable, $N(\%)$} & \multicolumn{4}{|c|}{ Multivariable, OR(95\% CI) } \\
\hline & $18-54$ years & 55-64 years & $\geq 65$ years & $P$ value & $\begin{array}{l}18-54 \\
\text { years }\end{array}$ & 55-64 years & $\geq 65$ years & $P$ value \\
\hline \multicolumn{9}{|c|}{ Hypertension treatment } \\
\hline Prior to stroke & $143(53.8)$ & $261(61.4)$ & $1156(61.7)$ & 0.046 & 1 & $1.88(1.29-2.76)$ & $1.68(1.21-2.36)$ & 0.029 \\
\hline 3 months & $108(68.8)$ & $197(73.8)$ & $649(64.1)$ & 0.010 & 1 & $1.28(0.75-2.19)$ & $0.81(0.50-1.29)$ & 0.058 \\
\hline 1 year & $116(71.2)$ & $183(71.8)$ & $558(66.0)$ & 0.143 & 1 & $0.97(0.56-1.70)$ & $0.80(0.49-1.31)$ & 0.247 \\
\hline \multicolumn{9}{|l|}{ Diabetes } \\
\hline Prior to stroke & $61(77.2)$ & $107(80.5)$ & $424(77.5)$ & 0.752 & 1 & $0.94(0.40-2.22)$ & $1.21(0.57-2.56)$ & 0.436 \\
\hline 3 months & $31(67.4)$ & $61(75.3)$ & $190(74.1)$ & 0.581 & 1 & $1.90(0.67-5.51)$ & $1.56(0.61-3.99)$ & 0.607 \\
\hline 1 year & $29(61.7)$ & $56(76.7)$ & $173(72.4)$ & 0.194 & 1 & $1.86(0.68-5.11)$ & $1.70(0.72-4.01)$ & 0.357 \\
\hline \multicolumn{9}{|l|}{ Atrial Fibrillation } \\
\hline Prior to stroke & $6(35.3)$ & $16(26.7)$ & $85(15.1)$ & 0.008 & & & & \\
\hline 3 months & $4(40.0)$ & $5(31.3)$ & $36(37.9)$ & 0.863 & & & & \\
\hline 1 year & $3(30.0)$ & $8(33.3)$ & $41(36.0)$ & 0.912 & & & & \\
\hline \multicolumn{9}{|c|}{ Antiplatelet therapy (IS) } \\
\hline 3 months & $146(71.6)$ & $228(78.1)$ & $910(77.8)$ & 0.131 & 1 & $1.24(0.78-1.99)$ & $1.44(0.96-2.15)$ & 0.071 \\
\hline 1 year & $165(79.0)$ & $254(81.2)$ & $825(77.3)$ & 0.327 & 1 & $0.95(0.57-1.60)$ & $0.83(0.53-1.30)$ & 0.309 \\
\hline
\end{tabular}

TABLE 5: Associations between age and continuing therapy and GP contact after stroke.

\begin{tabular}{|c|c|c|c|c|c|c|c|c|}
\hline & \multicolumn{4}{|c|}{ Univariable, $N(\%)$} & \multicolumn{4}{|c|}{ Multivariable, OR (95\% CI) } \\
\hline & $18-54$ years & 55-64 years & $\geq 65$ years & $P$ value & $\begin{array}{c}18-54 \\
\text { years }\end{array}$ & $55-64$ years & $\geq 65$ years & $P$ value \\
\hline \multicolumn{9}{|l|}{$\mathrm{PT} / \mathrm{OT}$} \\
\hline 3 months & $67(46.9)$ & $61(45.9)$ & $247(46.2)$ & 0.985 & 1 & $1.11(0.60-2.03)$ & $0.88(0.53-1.45)$ & 0.461 \\
\hline 1 year & $43(31.4)$ & $32(19.4)$ & $100(19.6)$ & 0.009 & 1 & $0.61(0.34-1.13)$ & $0.56(0.34-0.94)$ & 0.043 \\
\hline \multicolumn{9}{|l|}{ SALT } \\
\hline 3 months & $30(30.3)$ & $22(21.6)$ & $91(31.2)$ & 0.144 & 1 & $0.78(0.34-1.82)$ & $0.72(0.36-1.42)$ & 0.360 \\
\hline 1 year & $13(12.4)$ & $9(8.2)$ & $29(7.4)$ & 0.262 & 1 & $0.62(0.19-1.95)$ & $0.83(0.33-2.07)$ & 0.896 \\
\hline \multicolumn{9}{|l|}{ Seen by GP } \\
\hline 3 months & $198(77.0)$ & $237(82.9)$ & $760(68.8)$ & $<0.001$ & 1 & $1.54(0.93-2.53)$ & $0.67(0.45-1.00)$ & $<0.001$ \\
\hline 1 year & $163(86.2)$ & $164(84.1)$ & $505(79.0)$ & 0.045 & 1 & $1.06(0.52-2.16)$ & $0.72(0.39-1.32)$ & 0.167 \\
\hline
\end{tabular}


department." However, it also states that younger adults with stroke should be managed within settings that "recognise and manage the particular physical, psychological and social needs of younger patients with stroke" and that this should be "provided in an environment suited to their specific social needs." Results from this study suggest that the majority of younger stroke patients are receiving care on a specialist unit. While young patients with PICH are less likely to be treated on a stroke unit at any time during their stay, the majority are admitted to a neurosurgical ward or ICU instead. It has been suggested that the increased survival rates and lower levels of dependency associated with stroke unit admission are the greatest among the 18-64-year age group [14]. Although ICU may be deemed more appropriate for a younger patient, it is also important to ensure that they are not missing out on improved outcomes associated with stroke unit admission, afforded by specialist multidisciplinary stroke care.

A qualitative study of hospital and community stroke service providers looked at stroke unit admissions and selection procedures [22]. Service providers report that, even when policy states that all stroke patients be admitted, selection was occasionally required due to limited bed availability. In these cases providers commonly based selection on rehabilitation potential. Patients with mild strokes, likely to recovery quickly, and those with very severe strokes, deemed unlikely to recover, may be less likely to be admitted. Younger stroke patients may be deemed more likely to recover, potentially accounting in part for the higher rates of appropriate acute care observed. The greater perceived recovery potential of younger patients may also lead to longer contact with rehabilitation services as suggested by the higher rates of physiotherapy or occupational therapy 1 year after stroke in the 18-54-year age group. A qualitative study looking at stroke professional's attitudes to rehabilitation found elderly and unmotivated patients may be treated differently by some professionals, with greater encouragement to continue therapy potentially given to younger patients [23]. Younger patients themselves may also be more likely to push for ongoing rehabilitation therapies.

Although this study has not demonstrated any large differences in access to care according to age, with the exception of stroke unit admission for those with PICH, younger patients are more likely to report larger number of unmet needs and greater dissatisfaction with stroke services [24]. It is therefore important to ensure that existing services are meeting the needs of young people.

A study from the US found stroke survivors under 65 years of age were less likely to be seen by a general practitioner and less likely to be able to afford medications [8]. However, increasing age was associated with decreasing likelihood of being prescribed secondary prevention in the [9]. However, only stroke survivors aged 50 and over were included. In this study, there was no evidence of any differences in rates of secondary prevention and those under 65 were most likely to be seen by a GP.

A higher likelihood of having a brain scan in younger patients has previously been observed in other studies [1013]. No significant trend between age and odds of having a scan were found in this study although slightly higher overall rates were observed among younger patients. However, rates of brain imaging in this population were high; over $90 \%$ of all patients were scanned and this neared $100 \%$ towards the end of the study. Further, previous studies have focused on older stroke patients, categorising age differently.

A 2005 study using data from the SLSR, for the period 1995 to 2000, investigated patterns of care using similar indicators and reported that overall quality of care was suboptimal [1]. Another 2011 study looked at acute care services in the same area from 1995 to 2011 [10]. Significant improvements in care were found over the 15year period but inequalities still exist. This study focused on the younger patients, further dividing the under-65-year age group in two, to identify any further differences between younger people, more likely to be working, and those who may already be retired or have other comorbidities, while controlling for changes in uptake of services over time.

The main strengths of this study lie in its design. Data were obtained from a large multiethnic population-based register, estimated to be $75-84 \%$ complete [17], spanning a period of 16 years. While there is a number of populationbased studies that examine outcomes of stroke among working age or younger adults [25-27], to the best of our knowledge this is the first population-based study examining access to and provision of evidence-based stroke care for this age group.

The study is limited by the proportion of eligible patients completing the 3-and 12-month follow-up interview, $65.1 \%$ and $72.2 \%$, respectively. These rates are similar to those reported in other urban population-based studies [28, 29]. This study also relied on the self-report of the receipt of rehabilitation therapies and diagnosis of new risk factors at 3 and 12 months after stroke. This could be subject to recall bias as certain subgroups of patients may be less able to accurately recall new diagnoses or having received therapy.

Current SLSR data collection allowed us to compare access to evidence-based care that should be provided regardless of age. However, clinical guidelines also suggest that working age adults may have other needs not met by these services, which need to be identified and appropriate provision made available. Data on access to other services, such as vocational rehabilitation, was not available as part of this study. Further investigation of longer-term needs and outcomes of younger stroke survivors is needed to ensure current service provision reflects their priorities.

\section{Conclusions}

The majority of younger stroke patients have equal, or greater, access to evidence-based care when compared to older patients. However, the UK Department of Health's National Stroke strategy calls for the development of services to meet the particular needs of people who have a stroke in working age [29]. There is a need to ensure that evidencebased stroke services, such as stroke unit care, are meeting the needs of this group. 


\section{Acknowledgments}

The authore wish to thank all health care professionals, patients, and their families involved. Particular thanks go to the field workers collecting data for the SLSR since 1995. This project received funding from the Stroke Association and NIHR Programme Grant funding (RP-PG-0407-10184). The South London Stroke Register has also received funding from the Northern \& Yorkshire NHS R\&D Programme in Cardiovascular Disease and Stroke, the Guy's and St Thomas' Hospitals Charitable Foundation, the Stanley Thomas Johnson Foundation, The Stroke Association, and DH HQIP funding. This paper presents independent research commissioned by the National Institute for Health Research (NIHR) under its Programme Grants for Applied Research funding scheme (RP-PG-0407-10184). The views expressed in this paper are those of the author(s) and not necessarily those of the NHS, the NIHR or the Department of Health. The authors acknowledge financial support from the Department of Health via the National Institute for Health Research (NIHR) comprehensive Biomedical Research Centre award to Guy's \& St Thomas' NHS Foundation Trust in partnership with King's College London and King's College Hospital NHS Foundation Trust (to C. D. A. Wolf).

\section{References}

[1] C. McKevitt, C. Coshall, K. Tilling, and C. Wolfe, "Are there inequalities in the provision of stroke care? Analysis of an inner-city stroke register," Stroke, vol. 36, no. 2, pp. 315-320, 2005.

[2] M. A. Busch, C. Coshall, P. U. Heuschmann, C. McKevitt, and C. D. A. Wolfe, "Sociodemographic differences in return to work after stroke: the South London Stroke Register (SLSR)," Journal of Neurology, Neurosurgery and Psychiatry, vol. 80, no. 8, pp. 888-893, 2009.

[3] K. Daniel, C. D. A. Wolfe, M. A. Busch, and C. Mckevitt, "What are the social consequences of stroke for working-aged adults? A systematic review," Stroke, vol. 40, no. 6, pp. e431-e440, 2009.

[4] O. Saka, A. Mcguire, and C. Wolfe, "Cost of stroke in the United Kingdom," Age and Ageing, vol. 38, no. 1, pp. 27-32, 2009.

[5] Royal College of Physicians Intercollegiate Stroke Working, National Clinical Guidelines for Stroke, Royal College of Physicians, London, UK, 2008.

[6] A. Bhalla, R. Grieve, K. Tilling, A. G. Rudd, and C. D. A. Wolfe, "Older stroke patients in Europe: stroke care and determinants of outcome," Age and Ageing, vol. 33, no. 6, pp. 618-624, 2004.

[7] C. A. Di, M. Lamassa, G. Pracucci et al., "Stroke in the very old: clinical presentation and determinants of 3-month functional outcome: a European perspective. European BIOMED Study of Stroke Care Group," Stroke, vol. 30, no. 11, pp. 2313-2319, 1999.

[8] D. A. Levine, C. I. Kiefe, T. K. Houston, J. J. Allison, E. P. McCarthy, and J. Z. Ayanian, "Younger stroke survivors have reduced access to physician care and medications: National Health Interview Survey from years 1998 to 2002," Archives of Neurology, vol. 64, no. 1, pp. 37-42, 2007.

[9] R. Raine, W. Wong, G. Ambler et al., "Sociodemographic variations in the contribution of secondary drug prevention to stroke survival at middle and older ages: cohort study," British Medical Journal, vol. 338, Article ID b1279, 2009.

[10] J. Addo, A. Bhalla, S. Crichton, A. G. Rudd, C. McKevitt, and C. D. Wolfe, "Provision of acute stroke care and associated factors in a multiethnic population: prospective study with the South London Stroke Register," British Medical Journal, vol. 342, article d744, 2011.

[11] A. I. Lazzarino, W. Palmer, A. Bottle, and P. Aylin, "Inequalities in stroke patients' management in english public hospitals: a survey on 200,000 patients," PLoS One, vol. 6, no. 3, Article ID e17219, 2011.

[12] J. Heidrich, P. U. Heuschmann, P. Kolominsky-Rabas, A. G. Rudd, and C. D. A. Wolfe, "Variations in the use of diagnostic procedures after acute stroke in Europe: results from the BIOMED II study of stroke care," European Journal of Neurology, vol. 14, no. 3, pp. 255-261, 2007.

[13] A. G. Rudd, A. Hoffman, C. Down, M. Pearson, and D. Lowe, "Access to stroke care in England, Wales and Northern Ireland: the effect of age, gender and weekend admission," Age and Ageing, vol. 36, no. 3, pp. 247-255, 2007.

[14] A. Terent, K. Asplund, B. Farahmand et al., "Stroke unit care revisited: Who benefits the most? A cohort study of 105043 patients in Riks-Stroke, the Swedish Stroke Register," Journal of Neurology, Neurosurgery and Psychiatry, vol. 80, no. 8, pp. 881-887, 2009.

[15] Office for National Statistics, "2001 Census: Standard Area Statistics (England and Wales)," [computer file]. ESRC/JISC Census Programme, Census Dissemination Unit, Mimas (University of Manchester), 2003.

[16] J. A. Stewart, R. Dundas, R. S. Howard, A. G. Rudd, and C. D. A. Wolfe, "Ethnic differences in incidence of stroke: prospective study with stroke register," British Medical Journal, vol. 318, no. 7189, pp. 967-971, 1999.

[17] P. U. Heuschmann, A. P. Grieve, A. M. Toschke, A. G. Rudd, and C. D. A. Wolfe, "Ethnic group disparities in 10-year trends in stroke incidence and vascular risk factors: the South London Stroke Register (SLSR)," Stroke, vol. 39, no. 8, pp. 2204-2210, 2008.

[18] C. L. M. Sudlow and C. P. Warlow, "Comparing stroke incidence worldwide what makes studies comparable?" Stroke, vol. 27, no. 3, pp. 550-558, 1996.

[19] S. Hatano, "Experience from a multicentre stroke register: a preliminary report," Bulletin of the World Health Organization, vol. 54, no. 5, pp. 541-553, 1976.

[20] C. D. A. Wolfe, A. G. Rudd, R. Howard et al., "Incidence and case fatality rates of stroke subtypes in a multiethnic population: the South London stroke register," Journal of Neurology Neurosurgery and Psychiatry, vol. 72, no. 2, pp. 211216, 2002.

[21] J. Pal, R. Brown, and D. Fleiszer, "The value of the Glasgow Coma Scale and injury severity score: predicting outcome in multiple trauma patients with head injury," Journal of Trauma, vol. 29, no. 6, pp. 746-748, 1989.

[22] F. Mold, C. Wolfe, and C. McKevitt, "Falling through the net of stroke care," Health and Social Care in the Community, vol. 14, no. 4, pp. 349-356, 2006.

[23] N. Maclean, P. Pound, C. Wolfe, and A. Rudd, "The concept of patient motivation: a qualitative of stroke professionals' attitudes," Stroke, vol. 33, no. 2, pp. 444-448, 2002.

[24] R. Morris, "The psychology of stroke in young adults: the roles of service provision and return to work," Stroke Research and Treatment, vol. 2011, Article ID 534812, 2011.

[25] N. Glozier, M. L. Hackett, V. Parag, and C. S. Anderson, "The influence of psychiatric morbidity on return to paid work after 
stroke in younger adults: the auckland regional community stroke (ARCOS) study, 2002 to 2003," Stroke, vol. 39, no. 5, pp. 1526-1532, 2008.

[26] L. J. Kappelle, H. P. Adams, M. L. Heffner, J. C. Torner, F. Gomez, and J. Biller, "Prognosis of young adults with ischemic stroke: a long-term follow-up study assessing recurrent vascular events and functional outcome in the Iowa Registry of Stroke in Young Adults," Stroke, vol. 25, no. 7, pp. 1360-1365, 1994.

[27] H. Naess, H. I. Nyland, L. Thomassen, J. Aarseth, and K. M. Myhr, "Long-term outcome of cerebral infarction in young adults," Acta Neurologica Scandinavica, vol. 110, no. 2, pp. 107-112, 2004.

[28] H. M. Dewey, J. Sturm, G. A. Donnan, R. A. L. Macdonell, J. J. McNeil, and A. G. Thrift, "Incidence and outcome of subtypes of ischaemic stroke: initial results from the North East Melbourne Stroke Incidence Study (NEMESIS)," Cerebrovascular Diseases, vol. 15, no. 1-2, pp. 133-139, 2003.

[29] M. L. Niemi, R. Laaksonen, M. Kotila, and O. Waltimo, "Quality of life 4 years after stroke," Stroke, vol. 19, no. 9, pp. 1101-1107, 1988.

[30] Department of Health, National Stroke Strategy, Department of Health, 2007. 


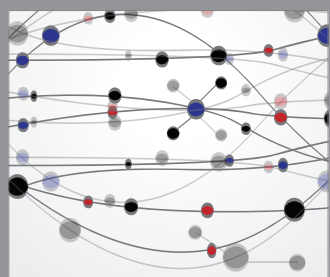

The Scientific World Journal
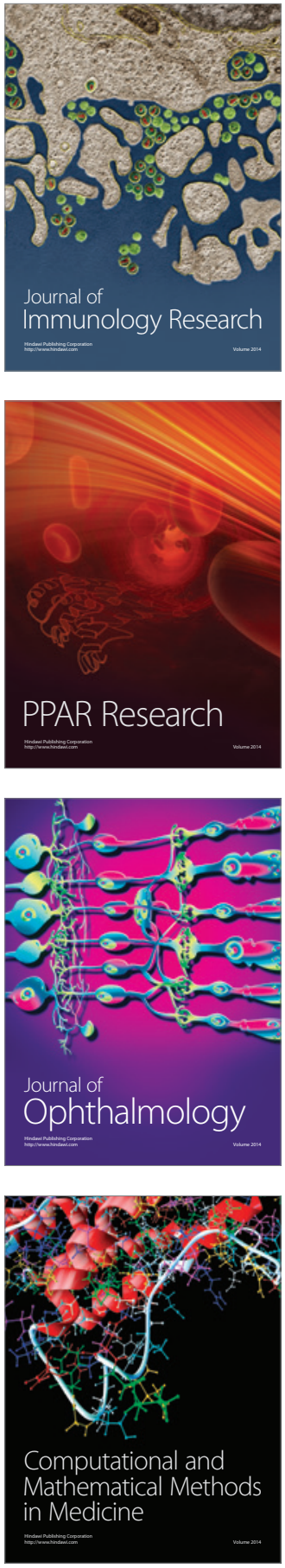

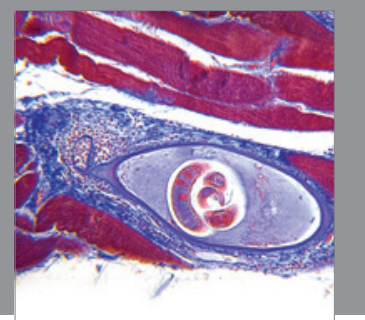

Gastroenterology

Research and Practice
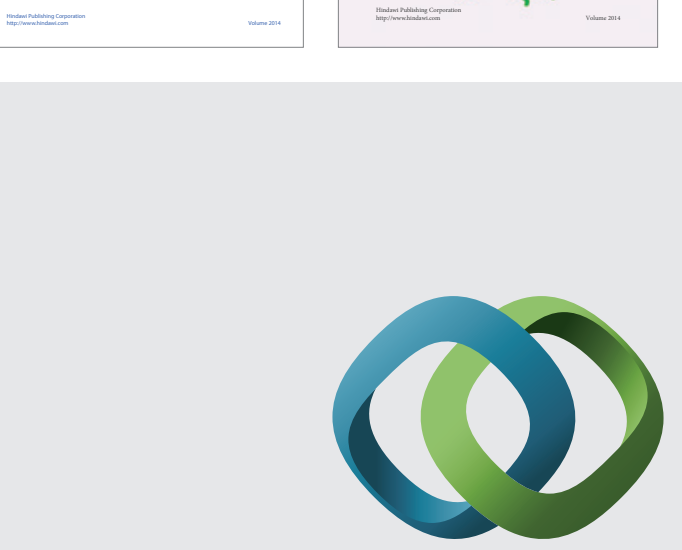

\section{Hindawi}

Submit your manuscripts at

http://www.hindawi.com
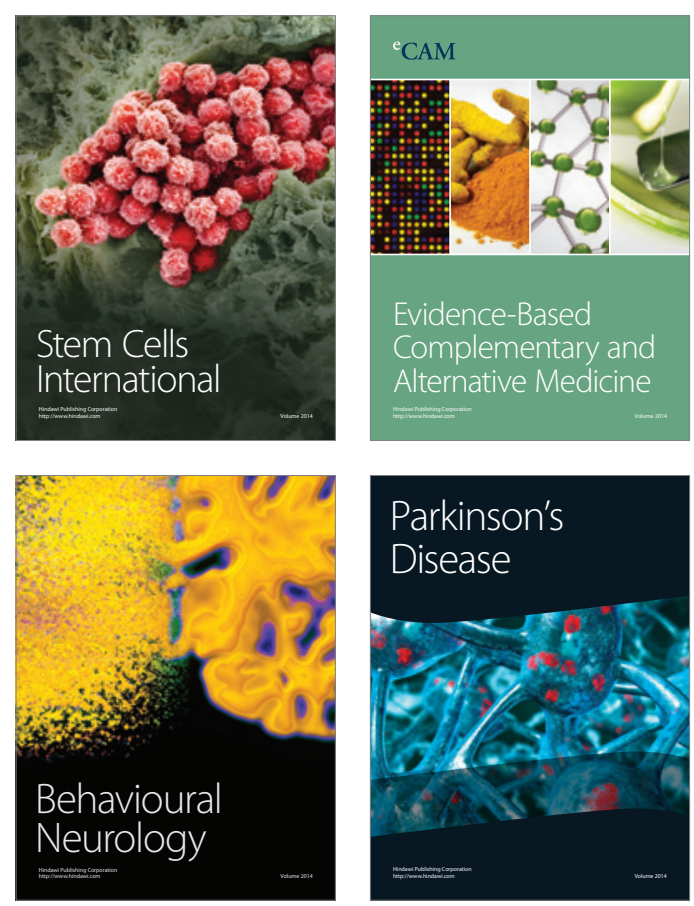

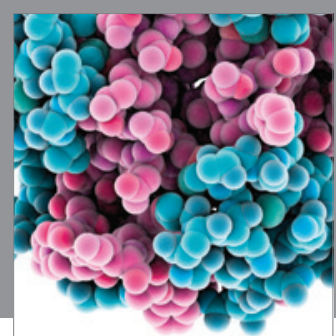

Journal of
Diabetes Research

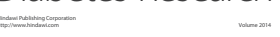

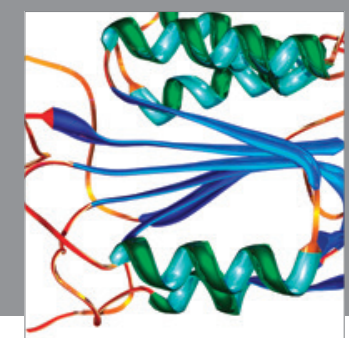

Disease Markers
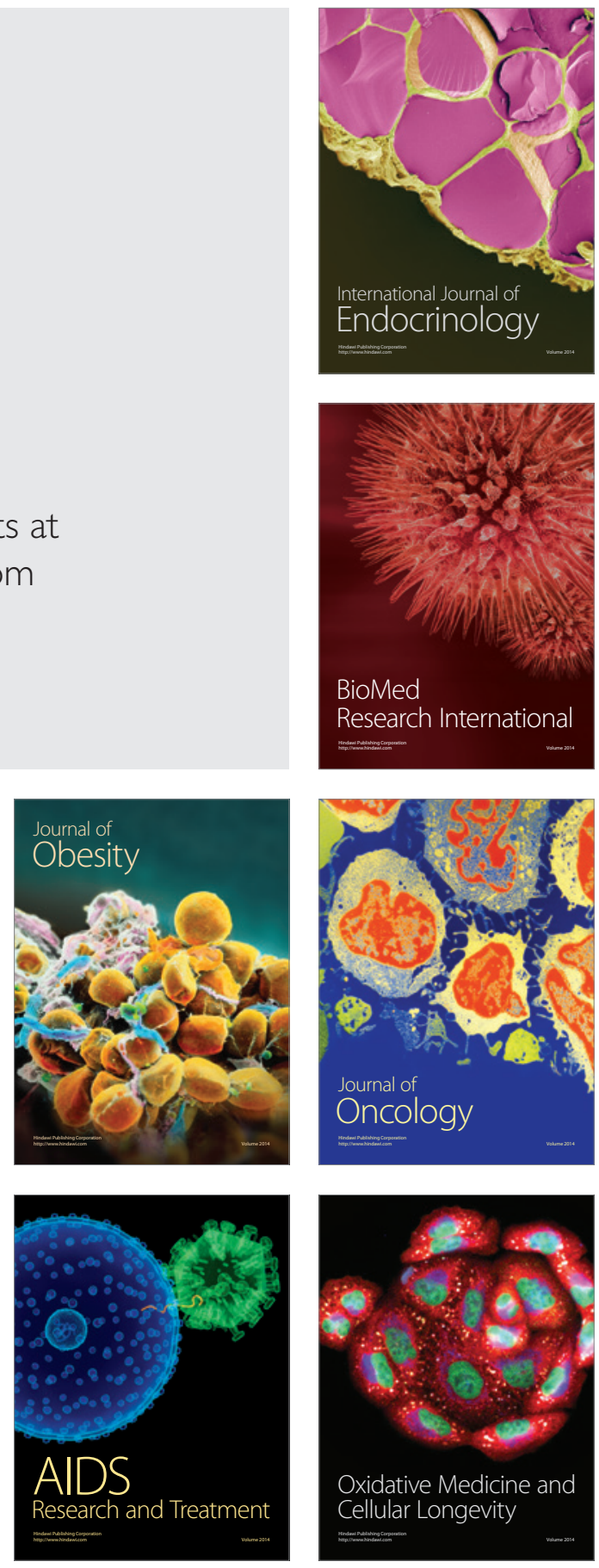